\title{
The Missed Opportunity of Primary Care Providers' Online Biographies: a Content Analysis of US Health Systems in 2020
}

\author{
Evan K. Perrault, Ph.D. (10, Jessie A. Barton, B.A., and Prince Adu Gyamfi, M.A.
}

Purdue University - Brian Lamb School of Communication, West Lafayette, IN, USA.

\begin{abstract}
BACKGROUND: Prospective patients are increasingly going to health systems' online directories to find their next primary care providers (PCP), making this channel of communication important to assess to determine if it is meeting patients' needs. When seeking a new PCP, patients want to know not only educational credentials but also providers' communication traits, and personal information to showcase providers as real people. Offering this information, to help patients find providers best suited to meet their needs, is a key attribute of patient-centered care.
\end{abstract}

OBJECTIVE: To analyze whether health systems' online PCP biographies are including the information prospective patients deem important when selecting a PCP.

DESIGN: Using the AHRQ's Compendium of US Health Systems, 523 health systems' PCP biographies were content analyzed ( $n=5004$ biographies) from December 2019 to March 2020.

MAIN MEASURES: Forty-eight unique pieces of information were coded for either their presence or absence (e.g., education, photo, languages spoken, insurance accepted, patient reviews, philosophy of care, video provided, personal hobbies/interests). Providers' alphabetic credentials (e.g., MD, DO, APRN) were also documented.

KEY RESULTS: The majority of biographies stated the provider's medical education (83.6\%) and included a photo $(81.4 \%)$. However, information patients also desire (e.g., communication traits and personal information) were less prevalent. Only 33.7\% listed languages spoken, $18.2 \%$ offered patient reviews, $14.4 \%$ had personal hobbies/interests, and 10.6\% included a video. There were also 192 unique alphabetic credential combinations listed next to providers' names. Two health systems clearly included information within biographies to help prospective patients understand what these credentials meant.

CONCLUSIONS: Health systems could make simple changes to their providers' online biographies in order to help patients make more informed decisions of PCPs. Doing so may decrease doctor shopping, and also lead to a greater likelihood of developing longer-term relationships with PCPs.

KEYWORDS: biographies; health care systems; websites; doctor shopping.

Prior Presentations Data from this paper were presented virtually at the 2020 Kentucky Conference on Health Communication

Received August 24, 2020

Accepted December 15, 2020

Published online January 19, 2021
$\mathrm{J}$ Gen Intern Med 36(10):3052-7

DOI: $10.1007 / \mathrm{s} 11606-020-06485-8$

(c) Society of General Internal Medicine 2021

\section{INTRODUCTION}

If selecting a new primary health care provider was an easy task for Americans, it is likely that the percentage of adults obtaining all recommended clinical preventive services would be much greater than just 8 -percent. ${ }^{1}$ Industry experts believe that in order to increase the uptake of preventive services there needs to be a "willingness of patients to seek out and engage in preventive care." (p. 3$)^{2}$ When patients attend a regular place of care, they are much more likely to receive preventive services. ${ }^{3}$ Additionally, seeing a general practitioner has been linked to increases in the frequencies of patients undergoing general health check-ups, including blood pressure checks and dental screenings. ${ }^{4}$ In other words, selecting a primary care provider is the first step for individuals to take control of their preventive health needs.

The next step involves building a strong relationship with a general practitioner. Long-term relationships with a primary care provider ( $\mathrm{PCP})$ are key to building patient-provider trust, which ultimately lead to patients attending more preventive office visits. ${ }^{5}$ However, building a relationship with a general provider is difficult to cultivate in a willing population when obtaining a mortgage, buying a new car, or finding a romantic partner can often be easier than finding a new health care provider. A recent survey by $\mathrm{ZocDoc}^{6}$ found that about half of millennials indicated maintaining a long-term relationship with a doctor is more difficult than with a romantic partner.

Insurance providers and government agencies advocate that one of the best methods for finding a new primary care provider is to schedule an in-person, face-to-face meeting, even though the provider likely will charge for this visit. ${ }^{7-9}$ However, this highly time-intensive activity is unlikely when Americans indicate it is sometimes hard to even find time just to sit down to eat a meal. ${ }^{10}$ Therefore, it is not surprising that one of the primary locations patients indicate they seek information about new health care providers when making their decisions is from the online biographies present on health care systems' websites. ${ }^{11}$ In theory, from the comforts of their own homes, patients should be able to easily and quickly click through biographies, looking for a provider who they feel can best fit their needs. This assumes, however, that providers' 
online biographies contain the information patients are actually looking for when making their selections.

Not surprisingly, the top trait prospective patients are looking for in a new provider is their education and credentials. ${ }^{6}$ However, after that, patients are looking for qualities in a new doctor similar to those they are looking for in a significant other (e.g., are they trustworthy, a good listener?). ${ }^{6}$ In other words, patients are concerned with the communication qualities of a future provider. ${ }^{12}$ Nearly a decade ago, Perrault and Smreker ${ }^{13}$ found in their content analysis of provider biographies from over 150 health systems that credentialing information, such as the medical school someone attended, was present in about $80 \%$ of biographies. Yet, information that could help a patient understand the communication traits of a new provider were lacking. Only about $30 \%$ of biographies indicated what language(s) the provider spoke, about $8 \%$ offered a philosophy of care where a provider might explain how they interact with patients, and about $3 \%$ provided a video of the provider where a prospective patient could actually witness how a provider communicates. ${ }^{13}$

The dearth of providers' online biographies including this important information is even more problematic because helping prospective patients easily select providers or practices most likely to meet patients' needs is a key component of providing patient-centered care. ${ }^{14}$ Given that technology has undoubtedly advanced since 2012 when Perrault and Smreker ${ }^{13}$ conducted their content analysis, as have the proliferation of boutique companies who uniquely specialize in the creation of content for health care organizations' provider biographies, the current study sought to see if the information landscape has changed for the better.

Patients also tend to seek providers with whom they can relate, and feel a level of perceived similarity. ${ }^{15}$ Showing patients that providers are just fellow human beings ${ }^{16}$ is one avenue toward achieving patient-centered care's "doctor-asperson" dimension. ${ }^{17}$ As Perrault ${ }^{18}$ found, the more similar new patients felt toward their providers, the greater degree of satisfaction they had with their first visits. One way patients can develop this sense of perceived similarity could be through the inclusion of personal information about providers within their online biographies.

Additionally, the landscape of primary care has also been changing dramatically over recent years. It is well documented that the USA is expected to face a primary care physician shortage of more than 20,000 in the next decade, meaning providers other than those with an MD or DO next to their names will likely need to absorb some of this workload. ${ }^{19}$ Providers such as NPs and PAs can perform many of the same duties as primary care doctors. However, patients' knowledge of the work these types of providers can perform (e.g., ability to prescribe medications, order lab tests, diagnose illnesses) is significantly less than their physician colleagues. ${ }^{11}$ Part of this lack of patient knowledge may be related to the sheer volume of alphabetic abbreviations that are placed next to providers' names (e.g., FNPBC, AGACNP, FACC, PMHNP-BC), and few organizations offering an explanation regarding what these abbreviations mean. ${ }^{20}$

Therefore, the purpose of our study was threefold: to determine (1) what information health care systems provide to patients about primary care providers; (2) how much personal information is provided; and (3) how health care systems report and explain credentials of their providers.

\section{METHODS}

\section{Sampling Frame}

In order to develop the sampling frame for the current study, the AHRQ's Compendium of US Health Systems was utilized. ${ }^{21}$ Two co-authors utilized this list to then find each health system's "find a provider" tool/site on their website. Of the 626 health systems listed by the AHRQ, the researchers were able to identify a "find a provider" tool for 523 health systems across the USA that yielded results for adult primary care providers.

Utilizing the "find a provider" tool, the researchers searched for "general medicine/practice"; "family medicine/practice"; "internal medicine"; and "primary care" in order to return search results of providers. Many times, the websites would auto-populate a term unique to the health care system to aid the researchers in finding primary care providers at those systems (e.g., general internal medicine, adult general medicine, family care, all primary care providers). To standardize the search process across systems, the researchers then recorded the names/links for the first 10 providers that appeared in the search. If there were fewer than 10 names present, all primary care providers' biographies were then ultimately coded. Utilizing this process, a total of 5004 primary care providers' biographies were compiled and coded by the researchers.

\section{Analysis and Coding Scheme}

In order to develop the coding scheme, the researchers started from the list of information Perrault and Smreker ${ }^{13}$ used to code biographies. After looking at hundreds of provider biographies individually and collectively as a research team, the final coding scheme contained 48 pieces of information. To gain confidence with the coding scheme, three rounds of coder training were conducted. During each round, two co-authors (JB, PAG) independently coded approximately 100 biographies, and intercoder agreement was then calculated by the first author. Given the fairly straightforward nature of the coding process, simply indicating the presence/absence of a piece of information within a biography, initial agreement was quite high. The coders met to resolve any disagreements and to also work through logistical considerations in coding the large volume of information (e.g., finding ways to re-order information within the coding document to increase efficiency). After the third round of training (overall Kappa: 0.930; overall percent agreement $=97.4 \%)$, the two co-authors 
independently coded the remainder of the biographies, about 2300 each. Coding began in December 2019 and was completed in March 2020.

\section{RESULTS}

The most frequently occurring pieces of information present within the biographies were the providers' listed specialty, office location/address, phone/fax number, and educational information (see Table 1 for a complete list of information coded). Regarding communication qualities of the provider, about one-third explicitly listed the languages the provider spoke. Other places where prospective patients might also be able to glean communication qualities of providers could also be in patient reviews/testimonials (18.15\%), philosophies of care $(14.33 \%)$, or a video of the provider $(10.57 \%)$.

Personal information about the provider was operationalized in the coding scheme through the inclusion of six different pieces of information: where the provider is originally from; where the provider currently lives; outside hobbies/ interests; marital status; a mention of children; and any statement regarding religion/faith. $16.9 \%$ of biographies $(n=846)$ included at least one piece of personal information about the

Table 1 Frequencies of Information Coded Within Biographies

\begin{tabular}{|c|c|c|c|}
\hline Information present & $n(\%)(N=5004)$ & $\begin{array}{l}\text { Coded in Perrault \& } \\
\text { Smreker }^{13}(N=1464)\end{array}$ & $\begin{array}{l}Z \text {-test of } \\
\text { proportions }\end{array}$ \\
\hline \multicolumn{4}{|l|}{ Presented in a majority of bios } \\
\hline Specialty listed & $4948(98.9)$ & & \\
\hline Office location-address - map & $4845(96.8)$ & $1370(93.6)$ & $5.63, p<.001$ \\
\hline Phone/fax number & $4813(96.2)$ & & \\
\hline Medical school (place where degrees earned) & $4184(83.6)$ & $1183(80.8)$ & $2.51, p=.012$ \\
\hline Picture/photo & $4074(81.4)$ & $1035(70.7)$ & $8.85, p<.001$ \\
\hline Residency/internships/fellowships & $3335(66.7)$ & $1079(73.7)$ & $-5.1, p<.001$ \\
\hline Board certification & $3246(64.9)$ & $1046(71.4)$ & $-4.67, p<.001$ \\
\hline \multicolumn{4}{|l|}{ Ways to learn provider's communication qualities } \\
\hline Languages spoken & $1684(33.7)$ & $435(29.7)$ & $2.83, p<.01$ \\
\hline Patient ratings (e.g., stars) & $1095(21.9)$ & & \\
\hline Patient reviews/testimonials - patient comments in own words & $908(18.2)$ & & \\
\hline Philosophy of care & $717(14.3)$ & $113(7.7)$ & $6.65, p<.001$ \\
\hline Video provided & $529(10.6)$ & $45(3.1)$ & $8.87, p<.001$ \\
\hline \multicolumn{4}{|l|}{ Personal information } \\
\hline Personal Hobbies_-interests noted_-pets & $719(14.4)$ & $92(6.3)$ & $8.22, p<.001$ \\
\hline Marital status & $315(6.3)$ & $33(2.3)$ & $6.03, p<.001$ \\
\hline Children & $314(6.3)$ & $34(2.3)$ & $5.90, p<.001$ \\
\hline Where originally from/born & $298(6.0)$ & $33(2.3)$ & $5.65, p<.001$ \\
\hline Where currently living & $181(3.6)$ & & \\
\hline Religion/statement about faith & $59(1.2)$ & $1(0.1)$ & $3.90, p<.001$ \\
\hline \multicolumn{4}{|l|}{ Additional information present } \\
\hline Make an Appointment & $1893(37.8)$ & & \\
\hline Shareable (e.g., share on Facebook, email it)_refer someone & $1732(34.6)$ & & \\
\hline Gender explicitly listed & $1350(27.0)$ & & \\
\hline Professional interests/medical conditions treated & $1328(26.5)$ & $365(24.9)$ & 1.23 , n.s. \\
\hline Insurance accepted & $1214(24.3)$ & $215(14.7)$ & $7.77, p<.001$ \\
\hline Hospital/clinic affiliation_medical home_privileges & $1149(23.0)$ & $489(33.4)$ & $-8.1, p<.001$ \\
\hline Accepting new patients & $1088(21.7)$ & & \\
\hline Professional societies & $528(10.6)$ & $151(10.3)$ & 0.26 , n.s. \\
\hline Office hours & $527(10.5)$ & $181(12.4)$ & $-1.97, p<.05$ \\
\hline Sees children & $523(10.5)$ & & \\
\hline Network affiliation & $475(9.5)$ & & \\
\hline Other positions they currently hold & $452(9.0)$ & & \\
\hline Number of years specifically at clinic/hospital & $334(6.7)$ & & \\
\hline Previous professional positions (where else worked) & $322(6.4)$ & & \\
\hline Number of years practicing & $317(6.3)$ & $162(11.1)$ & $-6.08, p<.001$ \\
\hline Link/button to "claim" bio and make changes - update profile & $268(5.4)$ & & \\
\hline Awards/recognitions & $222(4.4)$ & & \\
\hline Professional information (e.g., why they became a doctor) & $220(4.4)$ & & \\
\hline Publications & $127(2.5)$ & & \\
\hline Wellness tips & $126(2.5)$ & & \\
\hline NPI number & $102(2.0)$ & & \\
\hline Definition of specialty & $93(1.9)$ & & \\
\hline News clippings/stories & $85(1.7)$ & & \\
\hline Why they like working at the clinic-hospital & $62(1.2)$ & & \\
\hline Industry relationships & $42(0.8)$ & & \\
\hline Request a call & $33(0.7)$ & & \\
\hline Age & $30(0.6)$ & $74(5.1)$ & $-11.9, p<.001$ \\
\hline Email address & $22(0.5)$ & & \\
\hline Explanation of credentials (e.g., a hyperlink to definition) & $12(0.2)$ & & \\
\hline $\mathrm{CV}$-resume & $4(0.1)$ & & \\
\hline
\end{tabular}

Note: Perrault \& Smreker ${ }^{13}$ only coded physicians' biographies, which is likely why percentages for residency, board certification, and hospital affiliation are significantly lower in the current sample that looked at all varieties of PCPs (e.g., NPs, PAs) including physicians 
provider. The most frequently provided piece of personal information was providers' personal hobbies/interests $(n=$ $719)$, followed next by marital status $(n=315)$, children $(n=$ $314)$, and where they are originally from $(n=298)$.

There were a total of 192 unique alphabetic credential combinations listed next to providers' names. The most frequent credential was MD $(n=3162)$, followed by DO $(n=$ $762), \mathrm{PA}-\mathrm{C}(n=149), \mathrm{NP}(n=125), \mathrm{FNP}(n=110), \mathrm{APRN}(n$ $=87)$, PA $(n=65)$, and FNP-C $(n=48)$. (See Table 2 for a list of provider credentials that appeared more than once.)

The coders found two health systems-within 12

Table 2 Frequencies of Providers' Credentials

\begin{tabular}{ll}
\hline \hline Credential & $\boldsymbol{n}(\boldsymbol{\%})$ \\
\hline MD & $3162(63.2)$ \\
DO & $762(15.2)$ \\
PA-C & $149(3)$ \\
NP & $125(2.5)$ \\
FNP & $110(2.2)$ \\
APRN & $87(1.7)$ \\
PA & $65(1.3)$ \\
FNP-C & $48(1)$ \\
MD, FAAFP & $28(0.6)$ \\
MD, MPH & $28(0.6)$ \\
CNP & $27(0.5)$ \\
CRNP & $25(0.5)$ \\
APNP & $18(0.4)$ \\
FNP-BC & $16(0.3)$ \\
APN & $13(0.3)$ \\
ARNP & $13(0.3)$ \\
APRN, CNP & $11(0.2)$ \\
DNP & $11(0.2)$ \\
PHD & $9(0.2)$ \\
ANP & $8(0.2)$ \\
APRN-CNP & $8(0.2)$ \\
DDS & $8(0.2)$ \\
MD, PHD & $7(0.1)$ \\
NP-C & $7(0.1)$ \\
PAC & $7(0.1)$ \\
MBBS & $6(0.1)$ \\
MSN, FNP-C & $5(0.1)$ \\
APRN, FNP & $4(0.1)$ \\
DO, FAAFP & $4(0.1)$ \\
DO, MPH & $4(0.1)$ \\
RPA-C & $4(0.1)$ \\
APRN-C & $3(0.1)$ \\
DNP, FNP-C & $3(0.1)$ \\
MD, CMD & $3(0.1)$ \\
MD, MPH, FAAFP & $3(0.1)$ \\
MD, MS & $3(0.1)$ \\
MS, PA-C & $3(0.1)$ \\
MSN, APRN & $3(0.1)$ \\
MSN, FNP-BC & 2 \\
NP,S & 2 \\
RN, MSN, FNP-BC & 2 \\
AGACNP & 2 \\
APN, FNP & $20.1)$ \\
APN, FNP-BC & 2 \\
APRN, FNP-C & $3(0.1)$ \\
C-FNP & 2 \\
DNP, FNP & 2 \\
DO, MS & 2 \\
MD, ABFM & 2 \\
MD, FACP & 2 \\
MD, JD & 2 \\
MD, MSc & 2 \\
MSN, FNP & 2 \\
MSN, RN, CRNP, NP-C & 2 \\
RN, FNP & 2 \\
RN, FNP-BC & 2 \\
RN, MSN, FNP & 2 \\
RN, MSN, FNP-C & \\
\hline & 2 \\
\hline
\end{tabular}

biographies - that clearly included information that could help a prospective patient understand what these credentials meant. One health system included a link patients could click on titled "medical staff titles and terminology," and another system provided a paragraph titled "about physician assistants" underneath a biography of a PA, with a link to a brochure patients could download that explained what advanced practice providers (e.g., NPs, PAs, CNMs) are.

\section{DISCUSSION}

Today's health care consumers are actively using the internet to find information about future providers ${ }^{22}$ and expect health systems to offer online experiences similar to those they find in other consumer sectors. ${ }^{23}$ However, based on the current study's findings, health systems have some significant improvements to make to their online biographies in order to help guide patients in making the best choice of primary care provider for themselves. Not only will improvements ensure health systems are providing greater levels of patient-centered care, but helping patients more easily make this important decision can help ensure patients find the "right" provider the first time, and not have to shop around meeting providers in-person just to finally find their primary care provider. This is important because efficiently finding a provider patients want to continue seeing can likely lead to increased levels of continuity of care, which can ultimately lead to greater trust and improved health outcomes over time. ${ }^{24,25}$

For example, even though it is advocated to meet prospective providers in-person to judge a provider's communication style ${ }^{7-9}$ these sorts of meetings will usually only serve to consume precious time and resources of the health systems and patients, which is especially true during a pandemic such as COVID-19. Instead, an easier solution could simply be to offer short, introductory videos of primary care providers within their biographies, something only about $10 \%$ of biographies included. These types of videos do not even need to be that lengthy, as research indicates videos as short as $30 \mathrm{~s}$ can help patients decide whether or not they would be satisfied with a potential provider. ${ }^{26}$

Additionally, given the possibility of fake patient reviews, ${ }^{27}$ health systems can and should take some control back from third-party ratings websites and place genuine reviews and experiences from real patients within providers' biographies. Consequently, Americans tend to not put much trust in ratings of doctors or other care providers, with only about $10 \%$ stating that they "completely" or "trust very much" information provided by free-ratings websites. ${ }^{12}$ Only about 1 -in-5 biographies in our analysis provided reviews/testimonials from patients. In a world where it is getting more difficult to determine what is "real" on the internet, health systems are in a prime position to be the ones leading the way in cultivating genuine reviews, as they are an important gatekeeper that can verify 
whether the person posting was/is an actual patient of the provider.

The current analysis also finds that health systems could make very simple changes to their primary care providers' biographies that could help showcase their providers as real people, with families, hobbies, and interests outside of medicine. This type of personal information could help prospective patients find providers who share similar lived experiences, thereby helping them feel more comfortable disclosing their own information to providers during consultations to help them come to accurate diagnoses. ${ }^{28}$

Finally, health systems could be doing much more to increase the health literacy of the patients they serve by more clearly offering information to explain the numerous credentials of the primary care providers they employ. Credentials next to providers' names could have simple hyperlinks that link to a glossary of terms, or the organizations that oversee and authorize the credentials. Additionally, health systems could develop a page, similar to some student health centers, which offer explanations to patients (e.g., "what's in a name?"). ${ }^{20}$ It would likely also be helpful if there were more commonalities in the ways providers' credentials were presented across health systems, possibly only including the highest degree earned next to providers' names, or those most relevant to patient care.

One limitation to the current study was the selection process utilized to select providers' biographies. While the researchers identified and coded the first 10 biographies that a search returned to standardize the search process across the hundreds of health care systems - yielding over 5000 biographies - if systems alphabetized provider names, it is possible this process may have systematically led to coding more biographies from providers earlier in the alphabet. Future research of this type may seek to take a more computational approach to randomly select and code biographical content.

\section{CONCLUSION}

Comparing similar information coded by Perrault and Smreker ${ }^{13}$ nearly a decade ago in physicians' biographies, the content of today's provider biographies have improved slightly (see Table 1). A greater percentage of biographies now include philosophies of care, providers' personal hobbies/interests, and even video introductions of providers. However, this information is still only offered in fewer than $15 \%$ of all biographies coded. If health systems truly want to deliver patient-centered care to their patients, one of the first places they may want to look at improving is one of the first places their prospective patients are looking for information - health systems' own online provider biographies.

Corresponding Author: Evan K. Perrault, Ph.D.; Purdue University Brian Lamb School of Communication, West Lafayette, IN, USA (e-mail: perrault@purdue.edu).

\section{Compliance with Ethical Standards:}

Conflict of Interest: The authors have no conflicts of interest to disclose.

\section{REFERENCES}

1. Borsky A, Zhan C, Miller T, Ngo-Metzger Q, Bierman AS, Meyers D. Few Americans receive all high-priority, appropriate clinical preventive services. Health Affairs. 2018;37(6):925-8.

2. Levine S, Malone E, Lekiachvili A, Briss $\mathbf{P}$. Health care industry insights: why the use of preventive services is still low. Preventing Chronic Disease. 2019;16.

3. Bindman AB, Grumbach $\mathbf{K}$, Osmond $\mathbf{D}$, Vranizan $\mathbf{K}$, Stewart AL. Primary care and receipt of preventive services. J Gen Intern Med. 1996;11(5): 269-76.

4. Labeit A, Peinemann F, Baker R. Utilisation of preventative health check-ups in the UK: findings from individual-level repeated crosssectional data from 1992 to 2008. BMJ Open. 2013;12(3):1-17.

5. O'Malley AS, Sheppard VB, Schwartz M, Mandelblatt J. The role of trust in use of preventive services among low-income African-American women. Prev Med. 2004;38(6): 777-85.

6. ZocDoc. Match made in medicine: A peek into America's doctor-patient relationships. 2017. Available at: https://www.zocdoc.com/about/news/ match-made-in-medicine/. Accessed August 19, 2020.

7. BlueCross BlueShield. Five tips for choosing a new primary care physician. Available at: https://www.bcbs.com/five-tips-choosing-newprimary-care-physician. Accessed August 19, 2020.

8. National Institute of Health. How to choose a doctor you can talk to. Available at: https://www.nia.nih.gov/health/how-choose-doctor-youcan-talk. Accessed August 19, 2020.

9. United Healthcare. 10 tips for choosing a primary care doctor. 2017. Available at: https://newsroom.uhc.com/health/engagement/primarycare-doctor.html. Accessed August 19, 2020.

10. Pelletier JE, Laska MN. Balancing healthy meals and busy lives: Associations between work, school, and family responsibilities and perceived time constraints among young adults. J Nutrition Education and Behavior. 2012;44(6):481-9.

11. Perrault EK, Hildenbrand GM. Primary Care Confusion-Public Knowledge of NP and PA Duties and Their Information Gathering Behaviors. J Gen Intern Med. 2018;33(11): 1857-8.

12. Associated Press - NORC Center for Public Affairs Research. Finding quality doctors: How Americans evaluate provider quality in the United States. 2014. Available at: http://surveys.associatedpress.com/data/ NORC/AP-NORC_Provider\%20Quality_Topline.pdf. Accessed August 19, 2020.

13. Perrault EK, Smreker $\mathbf{K}$. What can we learn from physicians' online biographies to help in choosing a doctor? Not much. A content analysis of primary care physician biographies. J Comm in Healthcare. 2013;6(20): 122-7.

14. Davis K, Schoenbaum SC, Audet AM. A 2020 vision of patient-centered primary care. J Gen Intern Med. 2020;20(10):953-7.

15. Perrault EK, Silk KJ. The uncertainty reducing capabilities of primary care physicians' video biographies for choosing a new doctor: Is a video worth more than two hundred words?. Health Comm. 2016;31(12):147281.

16. Kulich KR, Berggren U, Hallberg LR. A qualitative analysis of patientcentered dentistry in consultations with dental phobic patients. J Health Comm. 2003;8(2):171-187.

17. Mead N, Bower P. Patient-centeredness: a conceptual framework and review of the empirical literature. Social Science \& Med. 2000;51(7):1087110.

18. Perrault EK. The utility of healthcare providers' online biographies for first-time patients: A year-long study within a clinical setting. Health Comm. 2020;35(10); 1283-88.

19. Association of American Medical Colleges. The complexities of physician supply and demand: Projections from 2018 to 2033. 2020. Available at: https://www.aamc.org/system/files/2020-06/stratcomm-aamc-physician-workforce-projections-june-2020.pdf. Accessed August 19, 2020.

20. Perrault EK. Campus health centers' lack of information regarding providers: a content analysis of division-I campus health centers' provider websites. Health Comm. 2018;33(7):860-6. 
21. Agency for Healthcare Research and Quality. Compendium of U.S. Health Systems, 2016. Available at: https://www.ahrq.gov/chsp/data-resources/compendium-2016.html. Accessed August 19, 2020.

22. Findlay SD. Consumers' interest in provider ratings grows, and improved report cards and other steps could accelerate their use. Health Affairs. 2016;35(4):688-96.

23. Kyruus. Consumerism is changing how patients find providers, according to new patient access research. 2017. Available at: https://www. kyruus.com/news/consumerism-is-changing-how-patients-find-providers-according-to-new-patient-access-research. Accessed August 19, 2020 .

24. Cabana MD, Jee SH. Does continuity of care improve patient outcomes? J Fam Pract. 2004;53(12):974-81.

25. Tarrant C, Dixon-Woods M, Colman AM, Stokes T. Continuity and trust in primary care: A qualitative study informed by game theory. The Annals Fam Med. 2010;8(5):440-6.
26. Perrault EK. The diminishing returns for longer healthcare provider video biographies: A thin slice examination of patient decision-making. Health Comm. 2020;1-9.

27. Shukla A, Wang W, Gao G, Agarwal R. Catch me if you can - detecting fraudulent online reviews of doctors using deep learning. SSRN. 2019. Available at: https://ssrn.com/abstract=3320258. Accessed August 19, 2020.

28. Perrault EK, Silk KJ. Reducing communication apprehension for new patients through information found within physicians' biographies. J Health Comm. 2015;20(7):743-50.

Publisher's Note: Springer Nature remains neutral with regard to jurisdictional claims in published maps and institutional affiliations. 